\title{
Type 2 diabetes can also be multigenerational like MODY
}

\author{
Viswanathan Mohan
}

Received: 19 July 2011 / Accepted: 22 July 2011 / Published online: 1 September 2011

(C) Research Society for Study of Diabetes in India 2011

Type 2 diabetes (T2DM) is now known to comprise of a heterogeneous group of metabolic disorders. The common garden variety of T2DM with onset in adult life is a multifactorial or polygenic disorder with multiple genes each playing a relatively minor role towards the overall risk of T2DM [1]. In addition, there is a large environmental component. Familial aggregation of T2DM is well known, and up to $40-60 \%$ of T2DM patients may have a family history of diabetes in a first degree relative [2]. This figure would obviously be higher if all the relatives were screened for diabetes rather than based on 'known' family history of diabetes. Multigenerational diabetes, with an autosomal dominant type of inheritance, is common in the monogenic forms of diabetes like Maturity Onset Diabetes of the Young (MODY) [3, 4]. Patients with MODY, typically have a diabetic parent and a grandparent, and often a great grandparent on the affected parent's side with diabetes, suggestive of autosomal dominant inheritance [5]. MODY type diabetes, is now classified into at least 6 distinct types (MODY-1 to MODY-6) based on the specific genetic mutation involved, although newer MODY types continue to be described $[6,7]$. MODY 3 (due to HNF1- $\propto$ mutations) is the commonest form of MODY followed by MODY-1 (due to HNF-4 $\propto$ mutations) and together they are believed to comprise up to $75 \%$ of adult onset MODY among Europeans $[3,4,6]$. In contrast, among Asian Indians while the

\footnotetext{
V. Mohan $(\triangle)$

Dr. Mohan's Diabetes Specialities Centre \& Madras Diabetes Research Foundation, WHO Collaborating Centre For Non-Communicable Diseases, International Diabetes Federation (IDF) Centre of Education,

4, Conran Smith Road, Gopalapuram, Chennai 600 086, India

e-mail: drmohans@diabetes.ind.in

URL: www.drmohansdiabetes.com

URL: www.mdrf.in
}

prevalence of MODY based on clinical criteria is high [8], MODY 3 mutations were seen only in $9 \%$ of clinically diagnosed MODY patients [9] while another 3.4\% had MODY 1 [10]. In these reports, some novel MODY 3 and MODY 1 mutations were also described. Thus it is clear, that the majority of clinically suspected MODY patients in India, either have other forms of MODY or, they may in fact, have an early onset form of T2DM.

The phenotype of MODY 3 and MODY 1 is characterized by overt, and often severe, diabetes [3, 4, 6, 7]. In contrast, MODY 2 due to glucokinase mutations, is a milder form of diabetes, often exhibiting just glucose intolerance (impaired glucose tolerance or impaired fasting glucose); it is usually asymptomatic and is picked up during routine screening of children or pregnant women [11]. Tattersall's cases, obviously carrying MODY 2 mutations, rarely progressed to diabetic complications [12] while MODY 1 and MODY 3, being more severe forms of diabetes were prone to develop microvascular complications like retinopathy or nephropathy $[6,13,14]$. Most forms of MODYare characterized by insulin secretory defects and insulin resistance is less common [15].

In contrast to MODY, early onset T2DM is a form of polygenic T2DM but with onset of diabetes at younger ages. As with classical T2DM, the predominant etiopathogenic mechanism in early onset T2DM is insulin resistance [16]. Patients with early onset T2DM often have diabetes in one or both parents, but unlike MODY, multigenerational transmission through the affected parent's side, is less common. Clinically, they tend to have features of insulin resistance such as obesity and acanthosis nigricans; in addition, features of polycystic ovarian disease are quite common in girls with early onset T2DM [16].

Till recently, it had been assumed that an autosomal dominant transmission of diabetes, with the classical multigenerational occurrence of diabetes, is restricted to the 
monogenic forms of diabetes like MODY [4]. Recently, our group reported a series of multigenerational autosomal dominant form of diabetes in south Indian T2DM subjects [17]. The age at diagnosis of diabetes in the probands with autosomal dominant multigenerational transmission of T2DM in that series was above 25 years of age in $77.4 \%$ of T2DM and above 45 years of age in $28 \%$ of T2DM. This is in contrast to MODY where the age at diagnosis is below 25 years according to the classical definition of MODY by Tattersal and Fajans [5]. Thus we showed that mere presence of multigenerational diabetes is not against the diagnosis of T2DM. In the same report, we also showed that there was no difference in the clinical and biochemical profile, or the prevalence of diabetes related complications, in T2DM patients with multigenerational diabetes compared to T2DM patients without multigenerational diabetes [17]. Another study from UK comparing family histories in South Asian and European T2DM subjects, also showed that autosomal dominant multigenerational diabetes was common among south Asians in the UK [18].

The minimal criterion for autosomal dominant inheritance is the occurrence of diabetes in two generations, although most families have at least three or more generations affected. In those with autosomal dominant inheritance, by definition, only one of the parents of an affected proband need be affected. Therefore, considerable caution should be exercised before defining a family in which both parents have diabetes as a MODY family, because children who inherit a "double gene dose" of T2DM from both parents tend to have an earlier onset of diabetes [16].

In this issue of the IJDDC, Irwing et al. [19] report on what they term "Mosaic Pancreas" or "type 3 diabetes". Essentially this is a case report of three probands from large families of multigenerational inheritance of early onset T2DM in at least 3 generations, detected at the University Hospital of the West Indies, Jamaica during a screening process for patients with MODY. The authors report that all the 6 MODY gene variants were absent in the three probands. Islet cell antibodies were absent in 2 of the 3 probands studied, but positive in one. The authors propose that these 3 cases could form a new type of diabetes which they propose to call "Mosaic pancreas" or "type 3 diabetes". While the cases described by the authors are certainly of interest, it would be difficult to justify labeling them as a separate class of diabetes in the absence of specific genetic or other diagnostic markers. One could argue, that but for the presence of multigenerational diabetes, there is nothing unusual about the probands 1 and 2 described in their report. Proband 3 with the ICA positivity may well have Latent Autosomal Diabetes of Adults (or LADA). It is known that some patients with diabetes present with what initially looks like T2DM but they have ICA or GAD positivity. These patients eventually require insulin and behave like type 1 diabetes (T1DM) and are called as LADA [20]. The authors propose the new term for their patients based on "heterogeneity" in the clinical presentation of T2DM. However T2DM is well known for its marked heterogeneity; for example, young or older age at onset; presence or absence of family history of diabetes; obese or non obese types; mild to marked insulin resistance; mild to marked insulin secretory defect and presence or absence of microvascular complications. Introducing a new terminology of diabetes based on the clinical findings presented, is therefore clearly unjustified. However, the report undoubtedly shows the heterogeneity in the clinical presentation of T2DM and underscores the need for more detailed studies on T2DM in different ethnic groups to fully characterize this complex disorder. It is likely that as our knowledge of the etiopathogenic mechanisms develop further, many cases presently classified as T2DM, may well fall into newer types or categories of diabetes and thus be removed from the "mixed bag" of what is currently lumped together under type 2 diabetes.

\section{References}

1. Prokopenko I, McCarthy MI, Lindgren CM. Type 2 diabetes: new genes, new understanding. Trends Genet. 2008;24:613-21.

2. Viswanathan M, Ramachandran A, Mohan V, Snehalatha C. Familial aggregation in diabetes mellitus - An analysis of 4000 cases. J Diabet Assoc India. 1977;17:9-13.

3. Fajans SS, Bell GI, Bowden DW, Halter JB, Polonsky KS. Maturity onset diabetes of the young (MODY). Diabet Med. 1996;13(9 Suppl 6):S90-5.

4. Vaxillaire M, Froguel P. Genetic basis of maturity-onset diabetes of the young. Endocrinol Metab Clin North Am. 2006;35:37184.

5. Tattersall RB, Fajans SS. A difference between the inheritance of classical juvenile-onset and maturity-onset type diabetes of young people. Diabetes. 1975;24:44-53.

6. Fajans SS, Bell GI, Polonsky KS. Molecular mechanisms and clinical pathophysiology of maturity-onset diabetes of the young. N Engl J Med. 2001;345:971-80.

7. Nyunt O, Wu JY, McGown IN, Harris M, Huynh T, Leong GM, et al. Investigating maturity onset diabetes of the young. Clin Biochem Rev. 2009;30:67-74.

8. Mohan V, Ramachandran A, Snehalatha C, Rema M, Bharani G, Viswanathan M. High prevalence of maturity onset diabetes of the young (MODY) among Indians. Diabetes Care. 1985;8:374-4.

9. Radha V, Ek J, Anuradha S, Hansen T, Pedersen O, Mohan V. Identification of novel variants in the hepatocyte nuclear factor 1 alpha gene in south Indian patients with maturity onset diabetes of young. J Clin Endocrinol Metab. 2009;94:1959-65.

10. Anuradha S, Radha V, Mohan V. Association of novel variants in the hepatocyte nuclear factor $4 \mathrm{~A}$ gene with maturity onset diabetes of the young and early onset type 2 diabetes. Clinical Genetics. 2010 Oct 18. doi:10.1111/j.1399-0004.2010.01577.x. [Epub ahead of print]

11. Froguel P, Zouali H, Vionnet N, Velho G, Vaxillaire M, Sun F, et al. Familial hyperglycemia due to mutations in glucokinase. Definition of a subtype of diabetes mellitus. N Engl J Med. 1993;328:697702 . 
12. Tattersall RB. Mild familial diabetes with dominant inheritance. Q J Med. 1974;43:339-57.

13. Velho G, Vaxillaire M, Boccio V, et al. Diabetes complications in NIDDM kindreds linked to the MODY 3 locus on chromosome 12Q. Diabetes Care. 1996;19:915-9.

14. Isomaa $B$, Henricsson $M$, Lehto $M$, et al. Chronic diabetic complications in patients with MODY 3 diabetes. Diabetologia. 1998;41:467-73.

15. Herman WH, Fajans SS, Ortiz FJ, Smith MJ, Sturis J, Bell GI, et al. Abnormal insulin secretion, not insulin resistance, is the genetic or primary defect of MODY in the RW pedigree. Diabetes. 1994;43:40-6.

16. O'Rahilly S, Spivey RS, Holman RR, Nugent Z, Clark A, Turner RC. Type II diabetes of early onset: a distinct clinical and genetic syndrome? Br Med J (Clin Res Ed). 1987;294:923-8.
17. Mohan V, Pranjali PP, Amutha A, Ganesan A, Datta M, Gayathri P. Prevalence and clinical profile of autosomal dominant type 2 diabetes from a diabetes centre in India. Prim Care Diabetes. 2009;3:233-8.

18. Mohan V, Sharp PS, Aber V, Mather HM, Kohner EM. Family histories of Asian Indian and European NIDDM patients. Pract Diabet. 1986;3:254-6.

19. Irwing R, Wright-Pascoe R, Mills JL, Choo-Kang EG, Mclaughlim WA, Mullings AA, et al. Mosaic pancreas or type 3 diabetes: how do we define it? Int J Diabetes Dev Ctries. 2011. doi:10.1007/ s13410-011-0028-0.

20. Nabhan F, Emanuele MA, Emanuele N. Latent autoimmune diabetes of adulthood. Unique features that distinguish it from types 1 and 2. Postgrad Med. 2005;117:7-12. 